\title{
LEADING MUSEUMS INTO A SUCCESSFUL DIGITAL TRANSFORMATION. RESEARCH ON EMERGING JOB ROLE PROFILES AND ASSOCIATED SKILL NEEDS; CONTRIBUTION OF THE MU.SA - MUSEUM SECTOR ALLIANCE PROJECT
}

\author{
P. Homem ${ }^{1}$, M. Pinto ${ }^{1}$, S. Medina ${ }^{2}$, P. Remelgado 3 \\ ${ }^{1}$ Faculty of Arts and Humanities of University of Porto (PORTUGAL) \\ ${ }^{2}$ Faculty of Engineering of the University of Porto (PORTUGAL) \\ 3 Pporto.pt (PORTUGAL)
}

\begin{abstract}
This contribution aims to present part of the research conducted within the Mu.SA - Museum Sector Alliance Project, funded by the Erasmus+ Programme and the Key Action 2 - Cooperation for Innovation and Good Practice Exchange (575907-EPP-1-2016-1-EL-EPPKA2-SSA). This research was built on results from the previous project eCult Skills (2013-15), funded under the Lifelong Learning Programme, aiming at identifying the emerging job role profiles for museum professionals and skill needs associated, as well as map them to the European Qualification Framework, Europe-wide but having the consortium participating countries (Greece, Italy and Portugal) as case-studies.

Four emerging job role profiles were identified: Digital Strategy Manager, Digital Collections Curator, Digital Interactive Experience Developer and Online Community Manager. For each, the skill needs were defined considering the e-Competences Framework, the Digital Competence Framework for Citizens (DigComp) and the 21st Century Skills, becoming the basis for the curriculum design of a MOOC and of a Specialization Course, combining e-learning, face-to-face and work-based learning phases.
\end{abstract}

Keywords: Museum professionals, Emerging job role profiles, Digital and transversal competencies, Mu, SA - Museum Sector Alliance Project. 